\title{
Distributed work and client/server computing: issues from the field
}

\author{
S Sawyer \\ and \\ $R$. Southwick \\ School of Information Studies \\ Syracuse University \\ Syracuse, NY 13244-4100 \\ Tel: 315-443-4473, Fax: 315-443-5806 \\ Email:ssawyer@syr.edu,rmsouthw@syr.edu
}

\begin{abstract}
One of information technology's most alluring promises lies in its potential for enabling knowledge work. The evolution of distributed computing has created an opportunity for knowledge workers to customize their rapidly evolving computing environment. In this new environment, highly sophisticated information tools are being brought directly into the hands of the office worker. It is widely believed that client/server $(\mathrm{C} / \mathrm{S})$ is the technology which will enable the successful implementation of distributed computing infrastructures. However, $\mathrm{C} / \mathrm{S}$ is not yet mature: tools and application are developing and adapting to client requirements as the process of building the $\mathrm{C} / \mathrm{S}$ infrastructure occurs. Moreover, it represents a paradigmatic movement away from the traditional, centralized models of computing (i.e., the mainframe). These factors suggest that the implementation of $\mathrm{C} / \mathrm{S}$ may bear a unique set of technical and organizational implications. In this paper we set forth some of the issues drawn from data collected in an ongoing, longitudinal study of information technology (IT) implementation at a mid-sized academic institution. This organization is in the midst of a multi-year project to migrate from a mainframe to a client/server computing environment. Issues derived thus far include the following: (1) C/S Implementation managers are currently 'straddling' the mainframe and C/S environments; (2) the C/S initiative appears to be primarily driven by technology; (3) the 'mindset' (mental models, cognitive processes) based on the mainframe model is still the basis for most clients (users), many developers, and some administrators; (4) there are unresolved issues of 'power' between IS managers, data custodians, and users; (5) there is a general trend toward distributed means of communication between members of the organization; and, (6) there is a growing awareness that end-user involvement is more time-consuming than expected.
\end{abstract}

\section{Keywords}

Organizational change, client/server, computing infrastructure 


\section{INTRODUCTION}

One of information technology's most alluring promises lies in its potential for enabling knowledge work (Drucker, 1994; Sproull \& Kielser, 1991). Dramatic advances in network technologies have made distributed forms of computing a practical reality for many of today's organizations (Hall, 1994). These distributed models have, in turn, spawned the development of new ways for members of organizations to accomplish their work: in forms of working together - individually and collaboratively - and in the types of work undertaken. Highly sophisticated information tools (for retrieval, storage, manipulation and communication) are brought directly into the hands of the office worker. In this rapidly evolving computing environment, knowledge workers are gaining increased levels of empowerment through their ability to access information, and control and customize their workplace.

Clearly, in this dynamic computing environment, there are a broad new spectrum of technical and organizational issues which will impact the management of work (Sproull and Kiesler, 1991). A considerable body of literature has accumulated which documents the ways in which information technology (IT) may affect both the physical forms and the work processes of organizations (Holsapple and Luo, 1995). Additionally, authors such as Orlikowski (1991) have pointed to the potential of IT to also enable cultural or social changes such as the redistribution of organizational 'power' or 'control'. She and others (e.g. Zuboff, 1988) portray this phenomenon as a 'flattening' of the traditional hierarchical organizational structure which results from a broadened access to strategic information among lower management and non-management organizational members. These literatures provide a basis for understanding the dynamic relationship between organizations and information technologies and may be extended to new distributed forms of computing.

In a distributed environment, data, hardware, software, and computer users form an interactive computing network - often across large geographic areas; computing functions are typically processed by more than one computer and control over processing is decentralized (Hall, 1994). In contrast to the traditional mainframe computing model, distributed models of computing seek to use the combined processing capability and storage of each computer that is connected to the network rather than giving exclusive control to a centralized master computer (i.e., the mainframe). The growth of the distributed environment is driven by the increased processing capabilities of desktop computers and the dynamic growth of network technologies.

The emergence of distributed models of computing may have important technical and organizational implications. First, it represents a paradigmatic change in the focus of computer technology. A "computer" must now be thought of as a network of components rather than as a singular piece of hardware. IBM's (a name synonymous with the mainframe) CEO, Louis Gerstner in elaborating his 'network-centric' vision of computing, states:

The first wave of computing, 30 years ago, was driven by the technologies of host-based processors [mainframes] and storage devices. Twenty years later, we moved into a second wave, which was driven by microprocessors and simplified operating systems. The third wave [current wave] of computing is being driven by very powerful networked technologies that provide very inexpensive and very wide [communications] bandwidth. (Business Week, 1995, p. 152).

Second, as alluded to above, the inherent potential for a more 'democratic' access to information may create a unique set of management issues as distributed computing architectures are adopted by organizations.

It is widely believed that client/server (C/S) is the technology which will enable the successful implementation of distributed computing infrastructures. However, while $\mathrm{C} / \mathrm{S}$ may represent the 'future' of computing, it is difficult to provide a precise definition. For the purposes of this paper we 
focus on C/S as software processes operating cooperatively, yet independently, in a peer-to-peer relationship. The client is the initiator of data interchange in this relationship, issuing requests for information as needed to the server or to other clients (Hall, 1994). In this view, C/S is one form of distributed computing.

Despite the rapid growth of client/server, little research has accumulated which highlights the issues inherent to implementing a $\mathrm{C} / \mathrm{S}$ computing architecture. In this paper we set forth some of the issues, and our views, drawn on the data collected from our ongoing study being conducted at a midsized academic institution (pseudonym 'Mid-Sized University' or MSU). The primary goal of this three year, longitudinal, field-based study (in progress) is to chronicle the organizational activities related to the move from the existing mainframe architecture to a client/server architecture.

Because the technical aspects of $\mathrm{C} / \mathrm{S}$ are in a dynamic state, we expect that there will be concurrent changes in the social environment of the organization (MSU) as well. There is little empirical data -- or even stories or anecdotes -- on organizational use of C/S as a computing infrastructure. And, as the technical constraints to access and distribution of data are removed, the social adaptations (organizational rules, departmental procedures, informal processes, and individual methods) to using $\mathrm{C} / \mathrm{S}$ will be critical in forming the new ways of working in this interconnected environment. Thus, the change to a $\mathrm{C} / \mathrm{S}$ infrastructure provides a unique perspective on how technology evolves, along with the social system in which it sits, as new ways of working arise. Stephen Barley (1986) said of his study of medical imaging technology: '...technology provides an occasion to structure.' We see the change to client server technology as an occasion to restructure at MSU.

Our focus in this research is on the reciprocal interactions and effects generated as a consequence of the change in computing infrastructure from mainframe-based to client/server-based, and the consequential changes within the organization. Our perspective on technology posits an interdependent relationship of negotiation between technology and the social structures within the organization. It is possible to adopt a framework for the study of organizational computing focusing on either of these perspectives independently. In other words, one may assume either a technological perspective in which technological change is viewed as driving the organizational structure, or an organizational perspective in which organizational needs determine technological innovation and implementation (Holsapple \& Luo, 1995). However, we feel that change is best understood by viewing both in their interaction.

Following on the work of Goodman and Sproull (1989) we see any technology (such as client/server) as being a system best described by the social and structural, as well as the technological issues which it comprises. While the technical challenges to building a successful infrastructure are critical and often daunting (Desai, 1995), we have chosen to focus on the social and structural issues in this stage of research. Our emphasis on the social and structural issues stems from our desire to better understand the use of C/S. Technical issues, in this context, are the basis for organizational decisions. In this paper we address:

How the managers (administrators) are adapting to the organizational changes (intended and unintended) brought on by the new computing infrastructure.

How the technologists (those who support and run the system) are adapting to the new infrastructure's demands.

We do not actively portray the end-user's perspective. Instead, we focus on how the technologists and managers are adapting to the changes brought about by the $\mathrm{C} / \mathrm{S}$ implementation. In doing so, however, end-user issues are revealed as central to both technologists and managers.

We believe that MSU's mainframe to client/server initiative offers a unique opportunity to study a phenomenon of relevance to the IT planning of many organizations. What follows in this paper is a 
brief historical background of the academic institution and a review of the theoretical and methodological bases for the study. We devote the bulk of this paper to some of the more salient issues derived from the data collected to this point. We also highlight our views on these issues.

\section{THE RESEARCH SETTING - MSU}

MSU is a private Carnegie Level II research school. It has a strong national and international reputation with high name recognition. MSU's administrative and organizational structures are typical for US universities of nearly 20,000 students. Employing nearly 3500 people, MSU is located on a large campus near the edge of a medium-sized city in the Northeastern US.

By 1993 three environmental factors created a context that demanded attention. MSU's vicepresident for computing (CIO), who managed both research and academic computing systems, faced: (1) an increasing demand on the mainframe systems; (2) a restrictive reliance on outdated legacy systems; and (3) a nearly unmanageable tangle of administrative and academic networks with overlapping links and disparate technologies. The constant evolution of available technology, a given in the computing business, is a fourth factor implicitly reflected in these other three issues.

The MSU also has several long-term contracts with vendors who support their legacy database products. Over the nearly 20 years these systems have served the university (primarily the administrative side of the organization), the constraints of the database systems and the cost of their upkeep have grown ever more limiting. Since these contracts are on a fixed cycle, the CIO wanted to affect infrastructure changes to coincide with the next renewal (Fall 1997).

The constrained service provided by the administrative systems (mainframe-centered and databasespecific) has contributed to a growth in local/departmental systems to support administrative computing. On the academic system side, the research computing network has always been decentralized at the school and departmental level. These local networks have been growing in number, expanding in size, and linking together. This has resulted in a systemic, but chaotic, expansion of departmental and research center computing infrastructure. This expansion, compounded with the increasing popularity of the Internet makes the strain on the computing infrastructure even more apparent. The proliferation of these local area networks is occurring even as the centralized administrative systems grow closer to being fully taxed.

MSU's issues with computing -- increasing demands on the mainframe, restrictive legacy systems, and explosive network growth -- are typical of most academic computing systems (Alpert, 1985). Facing this scenario MSU's CIO made the decision to revamp the computing infrastructure to take advantage of the new C/S architecture. As the CIO reflected this was, 'as much a decision on saving money as it was freeing ourselves from commitments we no longer wanted.' The steady rise in demand on the mainframes (processor time) was increasing faster than MSU could afford to upgrade. Since the software and service costs for MSU's mainframes were tied directly to the processors, any increase in processing power led to direct cost increases for existing software/services. In this period, MSU's IS staff was in regular contact with dozens of similar institutions that were facing the same issues. Regular contact between these organizations provided the CIO some of his information to aid in deciding on the C/S move. As he said, ' I am in regular contact with others in my same position, often on a weekly basis. We just decided to push ahead.'

The MSU's issues with computing also typify many non-academic organizations who face similar decisions about improving their computing infrastructure (Kling, 1990). Public entities such as governmental offices and utilities and for-profit organizations such as manufacturing and financial services are all confronted with constant pressure on the computing infrastructure. Moreover, the 
computing infrastructure of these organizations is an increasingly important aspect of the organizational operations. Recent estimates show that expenditures for computing systems average $8.4 \%$ of annual operating budgets. This percentage has been trending steadily upward since the inception of computer technology, and shows no signs of shrinking in the foreseeable future (Information Week, 1995).

As with many other mid to large organizations, much of the administrative work at MSU demands interaction between departments; the interdepartmental work is often an information intensive effort: for instance, as many as 12 views of a student's record may exist in disparate databases across MSU's campus; the work demands a high degree of knowledge and competency. Also, MSU's employees represent a mix of temporary and long-term employees. This arrangement, long an academic standard, is becoming increasingly popular with the modern organization. The core staff knows how to do their work -- and who to speak with to get that work done. With the changing computing infrastructure, the ways in which these workers accomplish their jobs will evolve as the C/S systems are understood and used.

\section{CONDUCTING THE STUDY}

\subsection{Method and plan}

The criteria which led to approaching MSU for this study center on the opportunity to observe the infrastructure change as it occurs. Since MSU has just begun this process, we can take the journey with the managers, technologists, and workers who are writing the story by their actions. In her book, In the Age of the Smart Machine, Shoshana Zuboff (1988, p.423) began the discussion of her methodology by saying: 'Behind every method is a belief.' Our belief is that in situ field work is an excellent method, well-suited for the type of research which seeks to understand the evolving process of implementing new technologies. This approach is becoming more common among present researchers. There has been an increased interest in longitudinal, field-based, and observer-centered research for the study of IT in organizations (Kling, 1980; Markus and Robey, 1988; Lee, 1995). This renewed interest has many reasons. Two of the most salient are (1) the limitations on what we know about technology's effects in organizations and (2) the speed at which technology changes. These issues echo the discussion by Ven de Ven and Huber (1990) as they introduce a special issue of Organization Science focused on longitudinal research methods. Our added focus is to use the change in technology (viz., implementation of $\mathrm{C} / \mathrm{S}$ ) as an opportunity to observe change in the organization.

We are pursuing a four-phased program of research (see Figure 1). The first stage has served to help us establish a context. This has included developing a history of the effort at MSU and of the people and organizational issues which have played a role in the genesis of the client/server initiative. It also serves as the context for interpreting the events and actions of the respondents as the infrastructure change occurs. The subsequent three phases are actually parallel tracks. Each of these phases centers on one group of participants. The first is the management team, which includes managers from across MSU. The second is the technology implementation team. This team includes both IS employees and users. This team also interacts with the management team and the work groups. The third team is a work group. This work group interacts with the technologists and is represented by their manager in the managerial group. The three follow-on phases of research focus on distinct levels and draw from the work of the first phase. Thus, the program of research provides 
the opportunity to triangulate findings across these three phases. In this paper we speak only of the data collected during our first phase.

\subsection{Data collection}

We have employed two primary methods for collecting data: interviewing and observation. Interviews vary by level of structure with most being semi-structured and open-ended. Typically these are taped and transcribed. Field notes are the data drawn from observation (as unobtrusive observer; as participant in committees and meetings; and through informal social interaction). There are two types of field notes for each period of observation: the first is a chronology of events and actions; the second is a more free-flowing account of perceptions, stories and anecdotes. The first serves as a record of observations. The second serves as a record of the observer's perceptions. We also have access to the formal documents and archives of the $\mathrm{C} / \mathrm{S}$ change. This includes the email traffic, work records and archival memos and reports.

The mainframe to client/server project was initiated by MSU in February 1993. We began our research effort in February 1995. To date our activities have centered on participation with, and observations of, committees formed to work on specific aspects of the $\mathrm{C} / \mathrm{S}$ initiative; ongoing interviews with managers (IS and other); and documentation collection. This includes more than 60 hours of meetings and over 20 interviews (averaging about 65 minutes each). We also have accumulated more than 180 documents (email, memos, handouts, and reports) and nearly 40 telephone conversations.

\section{PRESENT ANALYSIS AND FINDINGS}

As a result of these activities we have been able to conduct some preliminary analysis of the data. Our analysis has been developed through an iterative process of reflection and summarizing of the observations and interview notes. Source documents (memos, etc.) provided secondary support. In this section we describe some of our observations and discuss how each may be seen within the larger context of the organization and, more specifically, the C/S initiative (i.e., as 'issues').

\section{1 $\mathrm{C} / \mathrm{S}$ implementation managers are currently 'straddling' the mainframe and $\mathrm{C} / \mathrm{S}$ environments}

As with most IT implementations, the move from mainframe to $\mathrm{C} / \mathrm{S}$ at the MSU involves a gradual transition from one system to the other with considerable system overlap and gray area (in contrast to 'pulling the plug' on one system and 'plugging in' the other). This duality in the computing infrastructure has the effect of creating parallel roles for the IS managers; especially for those who are most heavily involved in affecting the change. On the one hand they are actively involved in the strategic planning and various implementation issues of the $\mathrm{C} / \mathrm{S}$ initiative. At the same time they must concern themselves with the day-to-day tactical decisions of the existing mainframe environment. A consequence of this added responsibility is that many of the high-level IS managers perceive that they are confronted with more work than they can handle. This is a matter of complexity as well as of work load. Not only is $\mathrm{C} / \mathrm{S}$ technology new and rapidly changing, it also requires an alternative mode of thinking (i.e., new mental models) in problem solving.

Inherent in this dilemma is the risk that in focusing their efforts on the these technical issues, the IS managers may lose sight of their role as agents of change. For instance, this issue is apparent in the 
relationship between IS managers and their programming staff. It is important for the managers to both instill a sense of the importance in adopting $\mathrm{C} / \mathrm{S}$ development techniques and at the same time to get the tasks at hand completed (largely mainframe related). Some IS managers have expressed a concern that some of their staff (i.e., some programmers) are reluctant to adopt the C/S model.

It is apparent that the amount of learning, the time to affect the transition, and the various sources of resistance are much larger and more persistent than expected. For instance, for those involved directly in the cross-over from mainframe to $\mathrm{C} / \mathrm{S}$, present roles include:

Learning new system(s) and the processes, methods, tools, applications, while building and maintaining this infrastructure. This is very close-to-home for some, looming as an issue for others, and tangential to a few.

Maintaining the present infrastructure. This varies from department to department. When (1) and (2) overlap it is the most difficult.

Acting as change agents with those who are involved in the transition at the present time. This seems to be more unexpected and difficult than anticipated.

Educating users of the new infrastructure.

The transition from mainframe to $\mathrm{C} / \mathrm{S}$ has had differing effects on managers depending on their level of involvement and general attitude toward change. For many of the highly involved IS managers, enthusiasm for change at the outset (or soon after) has often given way to a sense of sisyphusian effort: the $\mathrm{C} / \mathrm{S}$ rock never gets to the top of the change hill. Other IS managers have articulated that the changes will affect them at some point, but at present it has not. Their interest seems to be focused on minimizing the issues of change until they occur. Still other IS managers see this changeover as a way to expand and update the skills of their people and remain positive about the ultimate success of the new technology.

\subsection{The $\mathrm{C} / \mathrm{S}$ initiative appears to be primarily driven by technology at this point}

As participants in meetings of the high level managers, we have observed that technical issues tend to predominate. This is not surprising, as $\mathrm{C} / \mathrm{S}$ is a technology that is rapidly evolving, but also rapidly changing. Therefore, there is a high level of uncertainty inherent in all the decision-making, both at a tactical and at a strategic level. When asked to provide some definition or personal interpretation of $\mathrm{C} / \mathrm{S}$ during interviews, IS managers were generally vague. We interpret this, first, to the inherent ambiguity that is found in even the technical definitions provided in the literature. However, we also believe that this also reflects a state of mind toward the C/S initiative that is, in a sense, preconceptual. In other words, concrete technical issues rather than the broader organizational issues are currently at the fore in the minds of IS managers.

The entire project is based on a strategic decision which assumes that $\mathrm{C} / \mathrm{S}$ will become the predominant model (based on criteria which are largely technical). We perceive there to be a significant element of risk to the project if IS managers continue to be bogged down in technical issues and ignore user/organizational requirements. This risk is very real as we may expect the nascent $\mathrm{C} / \mathrm{S}$ technology (i.e., the development tools and miscellaneous software) to lag behind the user requirements - at least in the near future. This problem is further complicated by the fact that many of these requirements have been previously established and structured within the culture of the mainframe model and may not match or be appropriate within the $\mathrm{C} / \mathrm{S}$ model. Other requirements have emerged as part of the promise or mythology of the distributed model (of which C/S is a part) e.g., distributed multimedia - and may be difficult to deliver given current technological constraints.

The IS managers have been willing to make project plans based on assumption that new tools will become available as they are needed. A project strategy ('official' or de facto) which makes such 
assumptions - i.e., a reliance on the marketplace - may bear a degree of risk. Relying on the market may ultimately be successful, but not within the hoped-for time-line. This demands a high level of flexibility and a constant change to project plans for staffing.

A more sinister outcome of such a strategy, may be a creeping loss of credibility toward the administration and the technology by the clients if the technology doesn't 'work' within the current organizational environment. In light of the current state of the $(\mathrm{C} / \mathrm{S})$ 'art', it is critical that administrators, managers, and developers not allow their focus to become so narrow that they are only concerned with fixing technology and not staying aware of user requirements and problems. It will be especially important to maintain good lines of communication between technologists and clients. In the same vein, we believe that training initiatives may be especially important in convincing clients to 'buy in' to the $\mathrm{C} / \mathrm{S}$ initiative.

In sum, it is important that IS managers become active agents of change in their interactions with clients. This may present a challenge to them to the degree that it conflicts with their present identity within the organization (i.e., as technologist). It may require that they be much more interdependent, much more aware of the holistic issues with systems, and much less independent.

\subsection{The 'mindset' (mental models, cognitive processes) based on the mainframe model is still the basis for most clients (users), many developers, and some administrators}

This cognitive state has evolved through an ongoing (iterative) interaction between technology and people. As such, it has been strongly reified and is well established. C/S is disruptive to this world. This condition makes change difficult as people are 'speaking different languages.'

On the client side, this causes a problem with the 'requirements', which may be rooted in the mainframe model. For example, one of the many committees organized in response to the $\mathrm{C} / \mathrm{S}$ initiative generated a list of recommendations intended to facilitate the seamless transition from mainframe to $\mathrm{C} / \mathrm{S}$ at the organizational level. One of their recommendations was that printing continue to be done in a central location. This recommendation runs in direct conflict with the perceived (by IS) advantages of the C/S model - i.e., this (distributed printing) is the type of thing that $\mathrm{C} / \mathrm{S}$ enables. This illustrates the inherent conflict between a new technology and the structured work practices of an organization.

\subsection{There are unresolved issues of 'power' between IS managers, data custodians, and users}

A tenet of distributed computing is that users (clients) become more 'empowered'. They are able to make greater use of their desktop computers. The desktop becomes 'smarter,' allowing the user a greater access to information. However, in such an environment, how will the user be 'controlled'? Will controls be implemented through technology or management? If a technology approach is taken (exclusively), by concentrating primarily on ways to restrict user access, there is a risk that users will not 'buy into' the program. In which case, they will try to circumvent controls (rules) whenever it is possible or convenient. This is a real possibility because: (1) There are significant issues with access, security and control which are presently unsolved in the current state of C/S software - it is less evolved and far more complex than mainframe solutions in maintaining controls (security); (2) it must be remembered that - first and foremost - the clients have a job to do and are likely to take the path of least resistance.

Bottom line: a management approach to control must accompany a technology approach. The way to implementing a management approach to control is through a process of making the clients adopt 'responsibility'. That is, they must be made aware of the risks involved, and be made responsible for 
the consequences (personally as well as administratively). Toward this end, a program of education and training would seem to be critical. However, it is remains unclear as to the level of financial support and general commitment the administration wishes to provide such an effort. Most key technical decisions about topology and infrastructure are still controlled by IS, and as we have discussed, the primary focus of attention remains on technical issues. Interestingly, it also is unclear whether the user community understands the implications of these decisions or has any ability to involve themselves in these decisions if they did.

Another aspect of control seems to be that, while the IS directors are quite comfortable in discussing and sharing issues and decision-making, this does not seem to occur at lowers levels in each department. Most issues are coordinated through the managers. The informal coordination at the lower levels -- across departments -- may be increasing. For instance, the various standing committees have cross-departmental membership. Often, though, this is the only time many of these people converse.

\subsection{There is a general trend toward distributed means of communication between members of the organization}

Despite the lower level of informal cross-departmental communication in the IS departments, the increased level of distributed communication (email, voice mail) is very noticeable. This may have several sources independent of the $\mathrm{C} / \mathrm{S}$ effort (geographically distributed locations, more use of these communication media in general). However, three $\mathrm{C} / \mathrm{S}$-driven effects are noticeable. First, the increased interdependence between clients and IS demands more coordination and communication. Second, the increased reliance on vendors for products demands intra-organizational communication. Third, the rapidly evolving, and expanding, technologies demands tremendous communication and coordination. This creates an added level of bustle which is tied to the change in infrastructure. In fact, it is the direct consequence of the new infrastructure.

\subsection{Growing awareness that end-user involvement is more time-consuming than expected}

While this point can be subsumed under several others, our observations of several meetings encourages us to highlight this. While the concept of end-user involvement is central to much of the discussion in the IS manager meetings and in the interviews, the goals of this effort are less clear. User resistance to change based on technology, or to having more responsibility for their computing, is not as well-received as expected. Thus, the user 'pull' for this technology is less visible than the IS 'push' to implement.

Our basic approach to conducting this research is generally inductive (e.g. Yin, 1984); we have carried a theoretic framework into the investigation (Glaser and Strauss, 1967). As we have stated in this paper, our focus is on the reciprocal interactions between the incipient technology (i.e., C/S) and the organization. This is defined by work practices, rules, norms, etc. That is, by it's 'structures'. Accordingly, it is within this framework that we have interpreted a common thread running through all of the issues listed above. We see the interaction between technology and the organization viewed in terms of a technological 'push' and an organizational 'pull'. 
Technological Push. There is a drive - made manifest by administrative directive - to get to get the new $\mathrm{C} / \mathrm{S}$ architecture up and running. This drive originates in the assumption - held by technologists - that innovation in computer technology may directly impact organizations by providing better means of accomplishing work. As such, we view this aspect as originating in the 'folklore' of the technology - a folklore constructed by the larger society and, therefore, originating outside of the organization (Jackson, 1987). Within the organization, this drive - which we refer to as the 'push' of organizational computing - is championed by various administrators and managers.

Organizational Pull. We assume that there also exist a set of needs which may be derived, based on the work processes of the organization. This view is based on the organizational (versus technological) perspective referred to earlier in this paper. We see this as the 'pull' of organizational computing. This aspect of the dynamic is largely theoretically derived (versus empirically) in our research thus far, as we have not yet had the opportunity to observe or interview system users. Moreover, we assume that organizational needs may be dynamic, complex, and difficult to derive (Holsapple \& Luo, 1994).

Between these two forces lies the dynamic interplay. From our perspective the technological push should be counterbalanced by the needs of the technology users (organizational pull). In this view, it is not sufficient for a technology to merely possess a set of functionalities which may match the work processes of an organization. As we have illustrated in this paper, we feel it is necessary for the members of the organization to integrate the technology into their present social environment, and, ultimately, to restructure that environment and the technology until a proper fit is realized. In order for the technology users to integrate the technology, they must first embrace it. In order to embrace it, they must first understand it or at least be able to relate it to their work.

At MSU we see that the IS managers are currently preoccupied with technical issues in implementing C/S. Because they are unable to devote sufficient time or resources to their clients (or in the case of the IS managers, to their development staff), there is some question whether the $\mathrm{C} / \mathrm{S}$ technology will be embraced by the organization. In this state, since a balance cannot be achieved between technological push and organizational pull a third force appears: 'social inertia' or resistance to change. Although we have not yet had the opportunity to observe or interview users, we imagine that such resistance exists and may increase as pressures to meet project time-line objectives elevate the push to get the technology implemented.

Finally, a notable exception to the imbalance between technological push and organizational pull is found in issue 4.5 (above). That is, we have seen a trend toward distributed means of communication between members of the organization. We attribute two reasons for this situation: (1) The transition of this aspect of the infrastructure between mainframe and C/S has been relatively smooth. Electronic communication which had been previously established in the mainframe environment has gone through the initial phases of the structuring interaction between technology and the organization. This carries over to, and is amplified by, the C/S environment. (2) The adoption of electronic communication has progressed to a point where the needs are salient enough in the mind of the users so that the organizational pull (defined by needs) is exceeding the technological push and there is minimal social inertia.

6

\section{CONCLUSION}

To close, we emphasize that in presenting these issues it is neither our intention to draw definitive conclusions nor to make long range predictions with regard to the ultimate success or failure of the $\mathrm{C} / \mathrm{S}$ implementation, at MSU or any other organization. Our primary concern is to provide an 
accurate chronicle of the events as they unfold with the hope that our story may help to provide a 'road map' for this and other situations. As with any storytelling it is inevitable that certain 'themes' will emerge that help to guide the narrator toward the essential elements of the story - i.e., that which is 'important' (Van Maanan, 1995; Yanow, 1995; Barley, 1990).

In presenting these observations we hope to provide an indication of where we, as researchers, interpret the themes of importance to be in the MSU story. These will provide a guide for our future investigations in the present research. While guided by theory, we acknowledge that there may be as much intuitive artistry as science in our interpretations.

The six issues presented above appear to support one overlying theme. That is, technical issues -critical and difficult as they arise, occur in a context much broader, across more interdependent levels, than was imagined at the outset of this implementation. The professional staff, their management, and the administrators and users involved in this change provide a view of change at a personal, structural, and technological level. It is this interplay that drives this research.

Alpert, D. (1985). Performance and paralysis: The organizational context of the american research university. Journal of Higher Education, 56(3), 242-281.

Barley, S. (1986). Technology as an occasion for structuring: Evidence from observations of CT scanners and the social order of radiology departments. Administrative Science Quarterly, 31, 78108.

Barley, S. (1990). Images of imaging: Notes on doing longitudinal field work. Organization Science, 1(3), 220-249.

Drucker, P. (1994). The age of social transformation. Atlantic Monthly, 53-80.

Glaser, B., \& Strauss, A. (1967). The discovery of grounded theory. New York: Aldine de Gruyter. Goodman, P., \& Sproull, L. (1989). Technology and organizations. San Francisco: Jossey-Bass.

Hall, C. (1994). Technical foundations of client/server systems. New York: Wiley-QED.

Holsapple, C., \& Luo, W. (1995). Organizational computing frameworks: Progress and needs. The Information Society, 11, 59-74.

Information Week, 25, September 1995, p. 20.

Jackson, B. (1987). Field work. Urbana, IL: University of Illinois Press.

Kling, R. (1980). Social analyses of computing: Theoretical perspectives in recent empirical research. Computing Surveys, 12, 61-110.

Kling, R. (1990). More information, better jobs?: Occupational stratification and labor-market segmentation in the United States' information labor force. The Information Society, 7, 77-107.

Lee, A. (1995). (Special Call for Longitudinal Research). MIS Quarterly.

Lou Gerstner on catching the third wave. (1995, Oct 30). Business Week, p. 152.

Markus, M., \& Robey, D. (1988). Information technology and organizational change: Causal structure in theory and research. Management Science, 34(5), 583-598.

Orlikowski, W. (1991). Integrated information environment or matrix of control? The contradictory implications of information technology. Accounting Management \& Information Technology, $1(1), 9-42$.

Sproull, L., \& Kiesler, S. (1991). Connections: New ways of working in the networked organization. Cambridge MA: MIT Press.

Van de Ven, A., \& Huber, G. (1990). Longitudinal field research methods for studying processes of organizational change. Organization Science, 1(3), 213-219. 
Van Maanen, J. (1995). Crossroads: Style as theory. Organization Science, 6(1), 132-143.

Yanow, D. (1995). Crossroads: Writing organizational tales: Four authors and their stories about culture. Organization Science, 6(2), 224-237.

Yin, R. (1989). Case Study Research. Beverly Hills, CA: Sage Publications.

Zuboff, S. (1988). In the age of the smart machine: The future of work and power. New York: Basic Books.

\section{BIOGRAPHY}

Steve Sawyer is an Assistant Professor at Syracuse University's School of Information Studies. His research interests are on how groups work together and how they use technology. Over the past several years he has done research to understand how software developers acquire and use information technology to support their work. Steve's present research seeks to understand some organizational issues behind the use of distributed computing systems from managerial, developer, and user perspectives. He is a member of ACM, IEEE, INFORMS and the Academy of Management.

Richard Southwick is a Ph.D. student at the Syracuse University School of Information Studies. His research interests focus on IT-based organizational change and information user behaviors. 